\title{
Kontrol Kecepatan Motor Brushless DC Menggunakan Double Boost Converter Berbasis PI
}

\author{
Gita Arya Pratama ${ }^{1}$, M. Krisna Ramadhani Ananta ${ }^{2}$, Rio Winas Setia Budi ${ }^{3}$ \\ Belly Yan Dewantara ${ }^{4}$ dan Iradiratu D. P.K ${ }^{5}$ \\ Jurusan Teknik Elektro, Universitas Hang Tuah Surabaya, \\ Jl. Arief Rahman Hakim No. 150, Surabaya. \\ e-mail: aryaxiitpm@gmail.com, krisna.ramadhani1712@gmail.com, riowinas@gmail.com \\ bellyandewantara@gmail.com, iradiratu@hangtuah.ac.id
}

\begin{abstract}
Abstrak - Paper ini menampilkan desain double boost converter yang mempunyai kemampuan menggandakan tegangan dua kali lipat berturut turut beban DC yang menghasilkan tegangan output tambahan atau cadangan suplai pada beban. Pada umumnya double boost converter ini adalah konverter daya DC to Dc meningkatkan tegangan dari input (pasokan) ke output (beban) di desain menunjukkan bahwa dengan inputan sumber AC yang di searahkan terlebih dulu dengan converter penyearah berfungsi untuk mengatur kecepatan motor $B L D C$. Untuk pengontrolan pada beban motor menggunakan PI controller ( Proportional Integrator) dimana parameter PI controller diperoleh dari trial eror. PI controller juga berfungsi memperbaiki gelombang keluaran dan kecepatan motor $B L D C$.
\end{abstract}

Kata kunci : Motor BLDC, Double Boost Converter, PI controller.

\begin{abstract}
This paper features a double boost converter design that has the ability to double the successive voltage in a DC load which results in an additional output voltage or supply reserve at load. In general, this double boost converter is a DC to Dc power converter increasing the voltage from input (supply) to output (load) in the design shows that the input AC source is aligned first with the rectifier converter to regulate the speed of the BLDC motor. To control the motor load using a PI controller (Proportional Integrator) where the PI controller parameter is obtained from the trial error. The PI controller also functions to improve the wave output and speed of the BLDC motor.
\end{abstract}

Keywords: BLDC motor, Double Boost Converter, PI controller.

\section{PENDAHULUAN}

Pada era modern ini hampir semua sistem perangkat elektronik membutuhkan catu daya DC. Catu daya DC banyak digunakan pada sistem elektronika yang bertegangan rendah hingga sistem kelistrikan bertegangan tinggi. Namun pada penelitian ini converter yang digunakan adalah DC - DC yang dimana menggunakan sumber tegangan AC, maka dari itu dibutuhkan rangkaian rectifier. Penggunaan sistem catu daya DC memerlukan sistem yang mampu mengkonversikan tegangan DC dari suatu tingkat tegangan DC ke dalam bentuk tingkat tegangan DC yang lain. Untuk mengatasi permasalahan tersebut maka pada penelitian ini akan merancang sebuah alat converter tegangan DC yaitu Double Boost Converter DC-DC Bidirectional yang disertai dengan sistem kontrolnya dengan menambahkan PI control sebagai perbaikan gelombang keluaran, agar output tegangan yang dihasilkan konstan dan dapat dipertahankan dan dapat mengatur kecepatan pada motor BLDC.

\section{DASAR TEORI}

Motor Brushless DC (BLDC) adalah termasuk salah satu jenis motor DC, pada motor jenis ini tidak terdapat bagian sikat dan komutator. Motor Brushless DC ini termasuk dalam jenis motor sinkron, yang artinya medan magnet yang dihasilkan oleh stator dan medan magnet yang dihasilkan oleh rotor berputar pada frekuensi yang sama. Motor Brushless DC ini tidak mengalami slip seperti yang terjadi pada motor induksi biasa. Motor jenis ini mempunyai magnet permanen pada bagian rotor dan electromagnet pada bagian stator. Walaupun merupakan motor listrik sinkron 3 fasa, motor ini tetap termasuk kategori motor DC karena pada implementasinya motor Brushless DC ini menggunakan sumber tegangan DC sebagai sumber energy utama yang kemudian diubah menjadi tegangan $\mathrm{AC}$ dengan menggunakan inverter 3 fasa [3].

\section{A. Motor Brushless DC}

Motor brushless DC (BLDC) adalah jenis motor DC yang tidak memiliki sikat. Dengan dihilangkannya bagian sikat dan komutator, motor ini memiliki kelebihan antara lain adalah peningkatan pada efisiensi, pengurangan kebisingan yang ditimbulkan saat berputar, perawatan yang lebih murah, serta dapat berputar dengan kecepatan tinggi karena berkurangnya gesekan dengan sikat. Sedangkan kekurangan dari motor ini adalah lebih rumit dalam kontrolnya serta harga yang lebih mahal.

Secara konstruksi, motor brushless DC kurang lebih seperti motor AC sinkron magnet permanen, dimana belitan 
jangkar terletak pada stator dan rotor yang terdiri dari satu atau lebih magnet permanen, namun memiliki perbedaan pada back-EMF. Back-EMF motor AC sinkron magnet permanen berbentuk sinusoidal sedangkan motor brushless DC berbentuk trapezoidal. Dengan Back-EMF yang berbentuk trapezoidal tersebut, motor brushless DC dapat dikatakan memiliki karakteristik elektris seperti motor DC [3].

\section{B. Rectifier}

Penyearah tegangan atau yang biasa disebut dengan rectifier merupakan suatu bagian dari rangkaian catu daya atau power supply yang berfungsi sebagai pengubah tegangan AC (Alternating Current) menjadi tegangan DC (Direct Current). Rangkaian rectifier atau penyearah tegangan ini pada umumnya menggunakan dioda sebagai komponen utamanya. Hal ini dikarenakan fungsi dioda sebagai penyearah dan karakteristik utamanya yaitu melewatkan arus listrik ke satu arah dan menghambat arus dari arah sebaliknya. Rangkaian dioda sendiri jika dialiri tegangan AC maka akan melewatkan setengah gelombang dan setengahnya lagi di blokir.

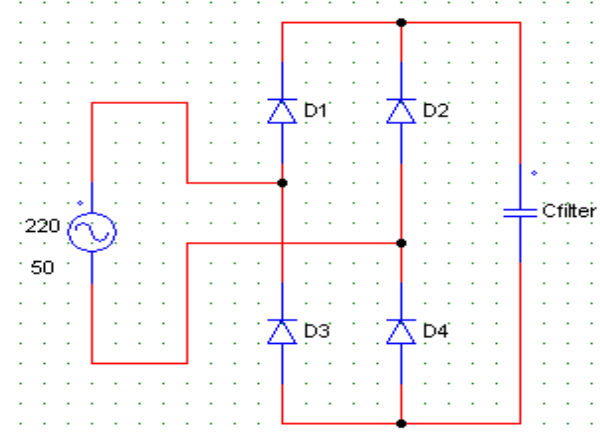

Gambar 1. Rangkaian Rectifier

\section{Double Boost Converter DC-DC}

Di penemuan yang baru ini, sistem penyimpanan energi menggunakan baterai telah banyak diteliti dan dikembangkan untuk sistem energi terbarukan. Untuk memaksimalkan energi yang tersimpan pada baterai tentu harus didukung dengan sistem transmisi energi dari baterai ke beban.

Rangkaian dasar dari double boost konverter dapat dilihat pada gambar berikut ini. konverter jenis ini mempunyai kemampuan menghasilkan tegangan output dua kali lebih besar daripada tegangan sumbernya.

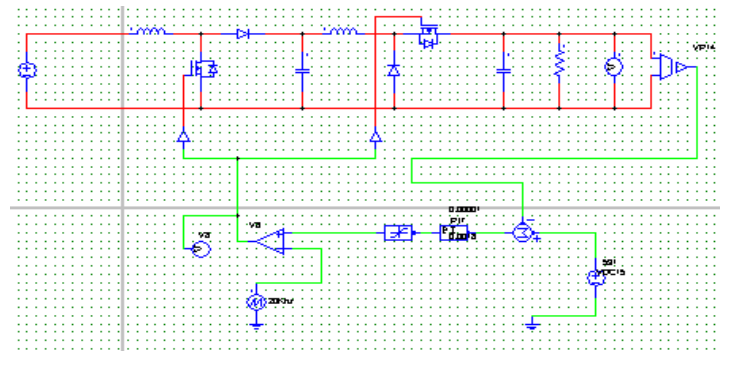

\section{Gambar 4. Rangkaian Double Boost Converter}

\section{Kontrol PI}

Sistem kontrol PI adalah kontroler untuk menentukan presisi suatu sistem instrumentasi yang menimbulkan karakteristik umpan balik pada sistem tersebut. Kontrol PI terdiri dari dua cara pengaturan yaitu kontrol $\mathrm{P}$ (proportional), dan kontrol I (Integral). Kontroler mencoba untuk meminimalkan kesalahan nilai waktu dengan melakukan penyetelan pada variabel kontrol.

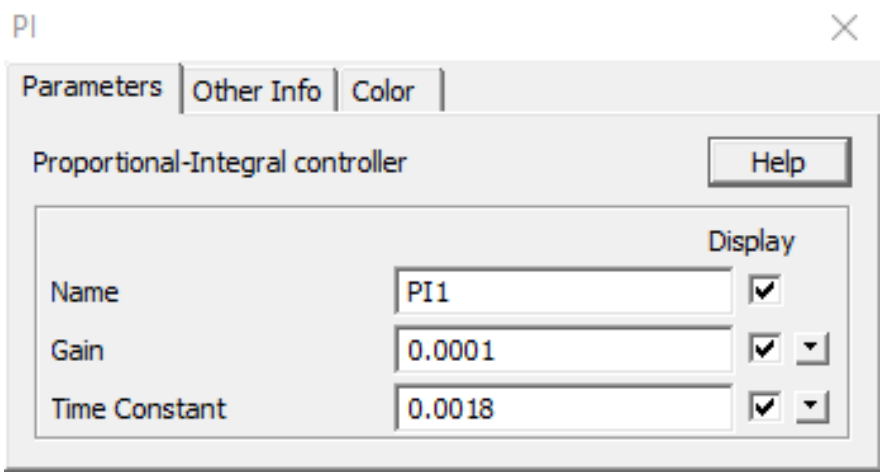

Gambar 2. Parameter PI

\section{METODE PENELITIAN}

\section{A. Konfigurasi Sistem}

Untuk melakukan pengontrolan pengontrolan pada motor BLDC dengan menggunakan double boost converter yang nilai output tersebut bisa dipertahankan agar menjadi stabil walaupun tegangan pada baterai mengalami penurunan kemudian dikendalikan dengan PID yang berfungsi untuk mengatur duty cycle mosfet sehingga tegangan ouput tetap stabil.

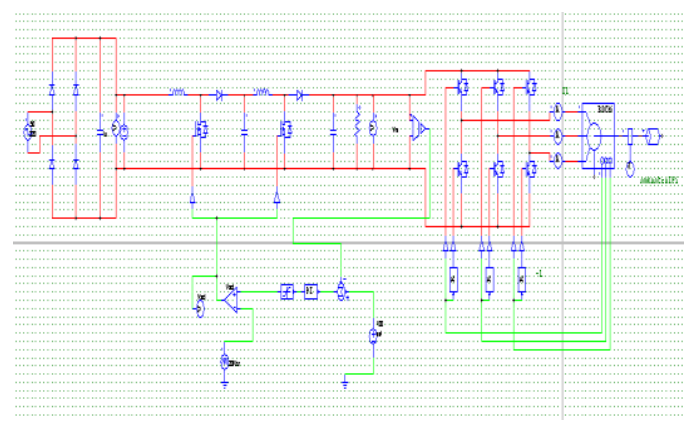

Gambar 3. Sistem kontrol BLDC secara keseluruhan

Motor yang digunakan dalam tugas akhir ini adalah motor brushless DC keluaran MOOG, seri BN42-53IP-03. Motor ini memiliki daya sebesar 874 Watt.

\begin{tabular}{|l|l|}
\hline Parameter & Nilai \\
\hline R ated Power & $874 \mathrm{Watt}$ \\
\hline Rated Speed & $2820 \mathrm{rpm}$ \\
\hline Rated Torque & $2.9588 \mathrm{Nm}$ \\
\hline Resistance & $0,408 \mathrm{Ohm}$ \\
\hline
\end{tabular}




\begin{tabular}{|l|c|}
\hline Inductance & $1.71 \mathrm{mH}$ \\
\hline Speed Constant $(\mathrm{krpm} / \mathrm{V})$ & 29.239 \\
\hline Torque Constant $(\mathrm{Nm} / \mathrm{A})$ & 0,3269 \\
\hline No. Of Poles & 8 \\
\hline Momen Of Inersia & $0,4939 \times 10^{-}$ \\
& ${ }^{3} \mathrm{Kg} \cdot \mathrm{m}^{2}$ \\
\hline No load Speed & $2920 \mathrm{rpm}$ \\
\hline No Load Current & $0,7 \mathrm{~A}$ \\
\hline
\end{tabular}

Tabel 1. Tabel Parameter Motor.

B. Perancangan Double boost konverter

Double boost konverter menggunakan sumber satu fasa $220 \mathrm{~V}$ yang disearahkan oleh diode bridge rectifier (DBR) yang setelahnya diberi kapasitor sebagai filter tegangan.

\begin{tabular}{|lc|}
\hline Tegangan Input & $220 \mathrm{~V}$ \\
\hline Tegangan Output & $100 \mathrm{~V}$ \\
\hline Daya Output & $875 \mathrm{Watt}$ \\
\hline Frekuensi & $50 \mathrm{KHz}$ \\
\hline Ripple Arus Masukan & $1 \%$ \\
\hline Ripple Arus Luaran & $1 \%$ \\
\hline Ripple Tegangan & $1 \%$ \\
\hline Induktor (L1) & $800 \mathrm{mH}$ \\
\hline Induktor (L2) & $800 \mathrm{mH}$ \\
\hline Kapasitor (C1) & $100 \mathrm{uF}$ \\
\hline Beban & $100 \mathrm{Ohm}$ \\
\hline
\end{tabular}

Tabel 2. Rating Double boost konverter

\section{Mencari Nilai Duty Cycle}

Berdasarkan tegangan input dan tegangan output yang telah ditentukan, maka duty cycle yang digunakan pada rangkaian cuk converter dapat ditentukan dengan persamaan berikut:

$$
\mathrm{D}=\frac{V_{o}}{V_{\text {in }}+V_{o} \cdot D}
$$

\section{E. Mencari Nilai Resistor (Hambatan)}

Selanjutnya akan ditentukan nilai beban yang digunakan pada rangkaian cuk converter, berdasarkan tegangan output dan daya output yang diharapkan, maka beban yang digunakan dapat dihitung dengan menggunakan persamaan berikut :

$$
P_{o}=V_{o} \cdot I_{o}
$$

\section{F. Mencari Nilai Induktor}

Setelah mengetahui nilai parameter dari rumus Daya, Tegangan, Arus, dan Beban. Barulah mencari nilai dari Induktor (L).

$$
\mathrm{L}=\frac{V i(i-D) D}{\Delta i f}
$$

\section{G. Mencari Nilai Kapasitor}

Setelah mengetahui nilai parameter dari rumus Daya, Tegangan, Arus, dan Beban. Baruralah mencari nilai dari Kapasitor (C).

$$
\mathrm{C}=(\mathrm{DVi}+\Delta \mathrm{V}) \cdot \frac{(i-D)}{f R \Delta V}
$$

\section{HASIL DAN PEMBAHASAN}

Simulasi dilakukan dengan menggunakan Software Power Simulator (PSIM). Dari hasil simulasi seluruh sistem dibuat analisa dan hasilnya berupa kecepatan dengan membandingkan hasil simulasi antara double boost konverter tanpa kontrol dengan terkontrol dan kestabilan kecepatan jika pada saat tanpa beban dan berbeban. Simulasi dalam Software PSIM ini bertujuan untuk menganalisa error study state, respon time, dan overshot dengan kecepatan yang berbeda-beda.

\section{A. Analisa respon kecepatan motor tanpa beban}

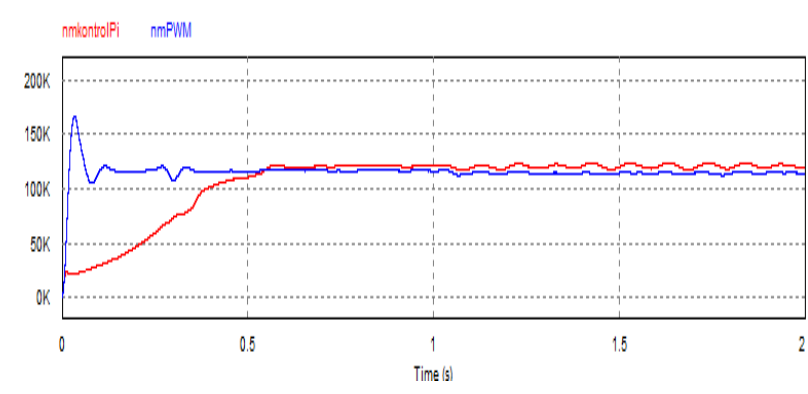

Gambar 7. Grafik Respon Kecepatan Motor Tanpa Beban

Dengan adanya perbandingan antara rangkaian double boost converter terkontrol, maka dibuktikan dengan adanya hasil grafik di atas yang dimana untuk warna merah terkontrol dan biru tidak terkontrol, untuk terkontrol mengalami start awal dengan halus dan tidak memiliki overshot, berbeda dengan tidak terkontrol yang mengalami start awal tinggi dan overshot $3.812 \mathrm{Mp}$ yang cukup tinggi dengan parameter kecepatan tanpa beban $=2000 \mathrm{rpm}$, respon time $=0.59$ detik.

\begin{tabular}{|l|l|l|l|c|}
\hline & Kecepatan & $\begin{array}{l}\text { Eror } \\
\text { steady } \\
\text { state }\end{array}$ & $\begin{array}{l}\text { Steady } \\
\text { state } \\
\text { time }\end{array}$ & Overshot \\
\hline $\begin{array}{l}\text { Tanpa } \\
\text { PI }\end{array}$ & $2000 \mathrm{rpm}$ & - & $0.34 \mathrm{~s}$ & $\begin{array}{l}3.371 \\
\mathrm{Mp}\end{array}$ \\
\hline PI & $2000 \mathrm{rpm}$ & $4.50 \%$ & $0.49 \mathrm{~s}$ & - \\
\hline
\end{tabular}

Tabel.3 Hasil perbandingan motor tanpa beban 
B. Analisa respon kecepatan motor dengan beban 0.1 Tc

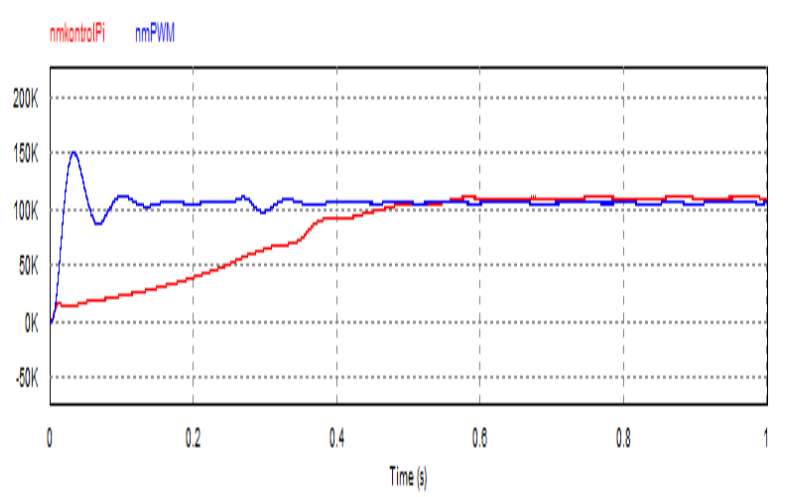

Gambar 8. Respon Kecepatan Motor berbeban 0.1 Tc

Dari gambar diatas dapat disimpulkan bahwa grafik rangkaian motor terkontrol menunjukkan kecepatan motor dengan kontrol kecepatan PI sebesar $2200 \mathrm{rpm}$ dan rangkaian motor tanpa kontrol PI menunjukkan

kecepatan sebesar $2200 \mathrm{rpm}$. Untuk rangkaian motor yang tidak terkontrol PI menghasilkan overshot sebesar 3.205. Respon time $=0.42$ detik, Eror study state $=3.3 \%$, Beban $=0.1 \mathrm{Tc}$, Overshoot $=3.595 \mathrm{Mp}$.

\begin{tabular}{|c|c|c|c|c|}
\hline & Kecepatan & $\begin{array}{l}\text { Eror } \\
\text { steady } \\
\text { state }\end{array}$ & $\begin{array}{l}\text { Steady } \\
\text { state } \\
\text { time }\end{array}$ & $\begin{array}{r}\mathrm{O} \\
\text { vers } \\
\text { hot }\end{array}$ \\
\hline $\begin{array}{l}\text { Tanpa } \\
\text { PI }\end{array}$ & $2400 \mathrm{rpm}$ & - & $0.36 \mathrm{~s}$ & $\begin{array}{r}3 . \\
812 \\
\mathrm{Mp}\end{array}$ \\
\hline PI & $2400 \mathrm{rpm}$ & - & $0.56 \mathrm{~s}$ & - \\
\hline
\end{tabular}

Tabel 4.Hasil perbandingan motor berbeban $0.1 \mathrm{Tc}$

C. Analisa respon kecepatan motor dengan beban 0.2 Tc

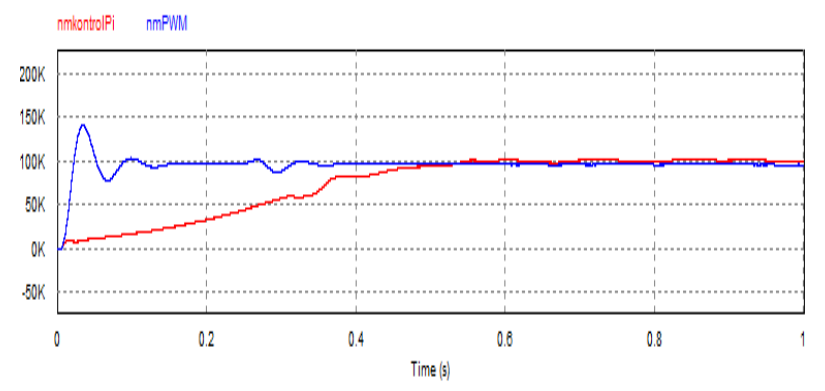

Gambar 9. Respon Kecepatan Motor berbeban 0.2 Tc

Dari gambar diatas dapat disimpulkan bahwa grafik rangkaian motor terkontrol menunjukkan kecepatan motor dengan kontrol kecepatan PI sebesar $2400 \mathrm{rpm}$ dan rangkaian motor tanpa kontrol PI menunjukkan kecepatan sebesar $188 \mathrm{rpm}$. Untuk rangkaian motor yang tidak terkontrol PI menghasilkan overshot sebesar 3.371.Untuk rangkaian motor yang tidak terkontrol PI menghasilkan overshot sebesar 3.371. Respon time $=0.59$ detik , Eror study state $=4.50 \%$, Beban $=0.2 \mathrm{Tc}$, Overshot $=3.595 \mathrm{Mp}$.

\begin{tabular}{|c|c|c|c|c|}
\hline & $\begin{array}{l}\text { Kecepat } \\
\text { an }\end{array}$ & $\begin{array}{l}\quad \text { Ero } \\
\mathrm{r} \\
\text { stead } \\
\text { y state }\end{array}$ & $\begin{array}{l}\text { Stea } \\
\text { dy } \\
\text { state } \\
\text { time }\end{array}$ & $\begin{array}{l}\text { Oversh } \\
\text { ot }\end{array}$ \\
\hline $\begin{array}{l}\text { Tan } \\
\text { pa PI }\end{array}$ & $\begin{array}{l}2200 \\
\mathrm{rpm}\end{array}$ & - & $\begin{array}{ll} & 0.35 \\
\mathrm{~s} & \\
\end{array}$ & $\begin{array}{l}3.595 \\
\mathrm{Mp}\end{array}$ \\
\hline PI & $\begin{array}{l}2200 \\
\mathrm{rpm}\end{array}$ & $\%^{3.3}$ & $\begin{array}{ll} & 0.55 \\
\mathrm{~s} & \end{array}$ & - \\
\hline
\end{tabular}

Tabel 5.Hasil perbandingan motor dengan beban $0.2 \mathrm{Tc}$

\section{KESIMPULAN}

Kesimpulan yang dapat ditarik dari hasil perancangan dan pengujian konverter double boost sebagai berikut:

1. Tegangan keluaran pada sisi output converter double boost dapat menaikkan tegangan dua kali lipat.

2. Semakin besar beban yang diberikan pada motor BLDC maka semakin besar eror steady state pada setiap kecepatan yang dihasilkan.

3. PI controller berfungsi memperbaiki gelombang keluaran pada kecepatan motor BLDC.

\section{DAFTAR PUSTAKA}

[1] Gunawan. "Rancang Bangun DC-DC Buck

Converter dengan PID Diskrit Sebagai Pengendali Tegangan Keluaran” UI, 2009.

[2] Friskarine Gity Cladella. Perbaikan Faktor Daya Pada Pengauran Kecepatan Motor Brushless Isolated-Cuk Konverter, 2017.

[3] JFJ van Rensbug, MJ Case, DV Nicolae. Power and Control Engineering Technology, 2018.

[4] Hadyan Perdana Putra, Heri Suryoatmojo, dan Sjamsjul Anam Perbaikan Faktor Daya Menggunakan Cuk Converter pada Pengaturan Kecepatan Motor Brushless DC, 2016.

[5] Ashari, Mochamad "Sistem Konverter DC'ITS Pers, Surabaya 2012.

[6] Nayar,MAshari, Phase Power Balancing of adiesel generator using a bidirectional PWM Inverter IEEE Power Engineering Review 19(11), 46-46, 1999.

[7] Setiawan Iwan, "Konrol PID Untuk Proses Industri" Elex media Kompotindo" 2008

[8] Ali Muhammad, " Pembelajaran Perancangan Sistem Kontrol PID dengan Software Matlab”Jurnal Edukasi@Elektro, Vol.1,No. 1 Oktober 2004. 